\title{
X-LINKED ADRENOLEUKODYSTROPHY \\ - a rare cause of Addison's Disease
}

Claudia Matta-Coelho ${ }^{1}$, Selma B. Souto ${ }^{1}$, Olinda Marques ${ }^{1}$

Endocrinology, Diabetes and Metabolism Department, Hospital de Braga, Braga, Portugal

\section{INTRODUCTION}

○ X-LINKED ADRENOLEUKODYSTROPHY (X-ALD) is a metabolic disorder caused by mutations in the ABCD1 gene leading to the accumulation of very long-chain fatty acids (VLCFA) in plasma and tissues

$\circ$ Estimated incidence of 1 IN 17.000 NEW-BORNS

- Clinical features are VARIABLE ranging from primary adrenal insufficiency and progressive myelopathy to cerebral demyelination

The authors report three cases of X-ALD confirmed by determination of VLCFA levels

CASE REPORT 1.

X-ALD diagnosed at 11 years old, patient discontinued medical follow-up at 25. After 3 years, admitted to the emergency department due to headaches, disorientation and urinary retention. Magnetic resonance imaging (MRI) showed active areas of demyelination.

Normal previous MRI.

After 2 years, patient is in a persistent vegetative state. Family history revealed brother with $X$ -

ALD, and mother and sisters carriers.

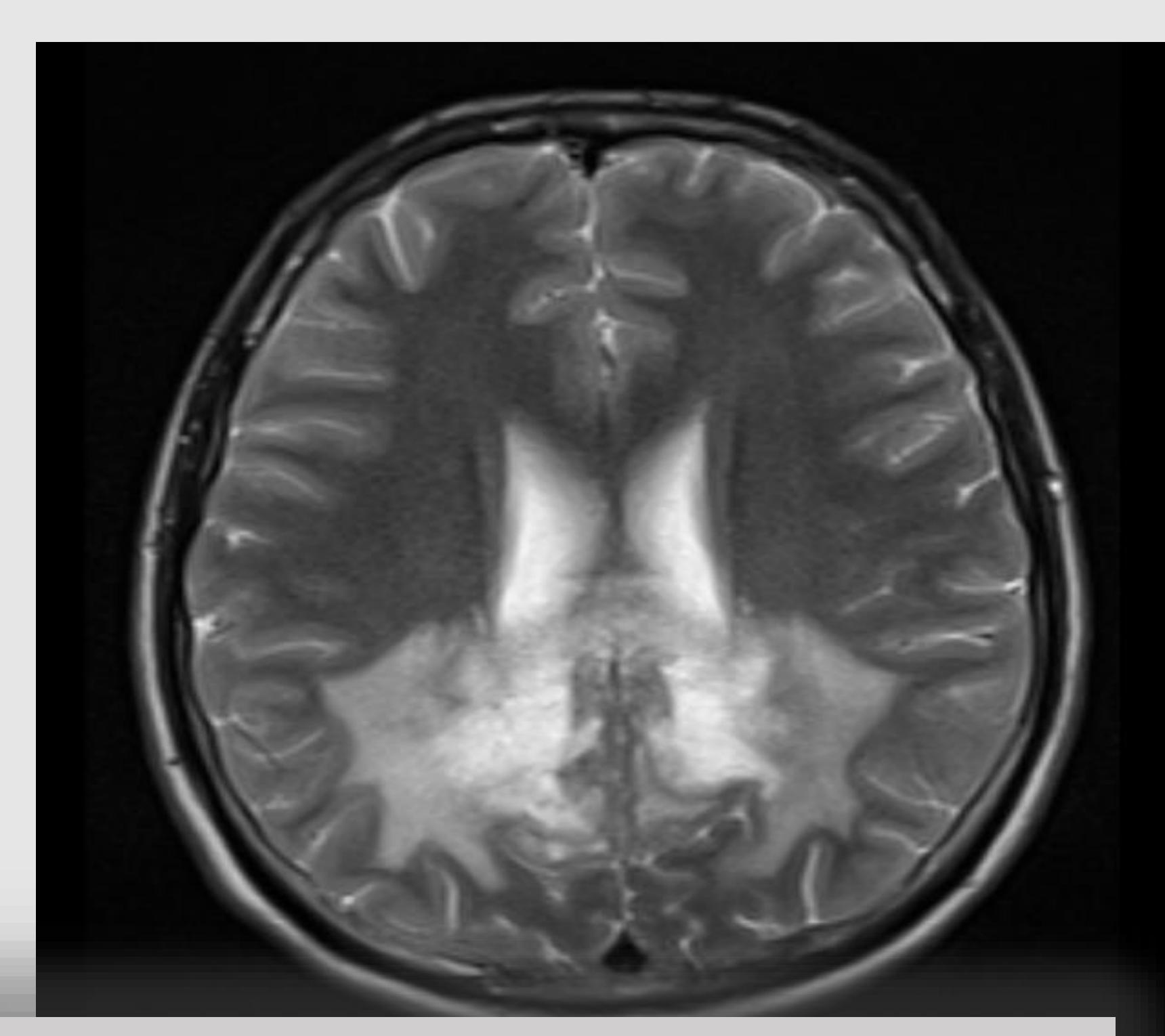

Image 1 - Brain MRI (Axial T1) In both parietal regions it is visible the change of signal involving the periventricular white matter with subcortical extension
CASE REPORT 2.

$\mathrm{X}$-ALD diagnosed at 22 years old with primary adrenal insufficiency.

His mother is a carrier and there is a high suspicion of maternal uncle death due to X-ALD at 22 years old.

At 32 years old, reference to sporadic headaches and vertigo. Normal MRI, however myelopathy confirmed by brainstem auditory evoked potentials.

\section{CASE REPORT 3.}

X-ALD diagnosed at 28 years old with primary adrenal insufficiency. Personal medical history of epilepsy.

At 44 years old, remains with no clinical manifestations of myelopathy or physical examination abnormalities Normal magnetic resonance. 